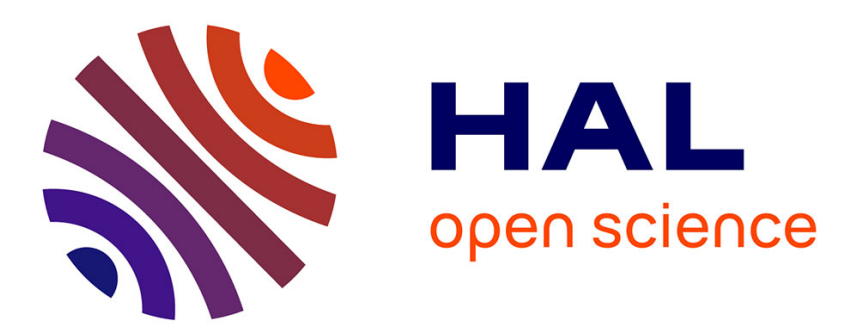

\title{
Flash-induced ATP synthesis in pea chloroplasts in relation to proton flux
}

\author{
Claire Lemaire, Guy Girault, J.M. Galmiche
}

\section{To cite this version:}

Claire Lemaire, Guy Girault, J.M. Galmiche. Flash-induced ATP synthesis in pea chloroplasts in relation to proton flux. Biochimica biophysica acta (BBA) - Bioenergetics, 1985, 807 (3), pp. 285 292. 10.1016/0005-2728(85)90260-9 . cea-02931634

\section{HAL Id: cea-02931634 https://hal-cea.archives-ouvertes.fr/cea-02931634}

Submitted on 7 Sep 2020

HAL is a multi-disciplinary open access archive for the deposit and dissemination of scientific research documents, whether they are published or not. The documents may come from teaching and research institutions in France or abroad, or from public or private research centers.
L'archive ouverte pluridisciplinaire HAL, est destinée au dépôt et à la diffusion de documents scientifiques de niveau recherche, publiés ou non, émanant des établissements d'enseignement et de recherche français ou étrangers, des laboratoires publics ou privés. 


\title{
Flash-induced ATP synthesis in pea chloroplasts in relation to proton flux
}

\author{
C. Lemaire, G. Girault and J.M. Galmiche * \\ Service de Biophysique, C.E.N. Saclay, 91191 Gif-sur-Yuette Cedex (France)
}

(Received November 5th, 1984)

Key words: ATP synthesis; ATP synthase; Proton flux; (Pea chloroplast)

Chloroplasts extracted from preilluminated pea seedling leaves have an active ATP synthase. Single turnover flashes induce ATP synthesis in these chloroplasts. This synthesis has been measured by the luminescence of the luciferin-luciferase assay system and the absorbance changes at $515 \mathrm{~nm}$ monitored to determine the concomitant proton flux through the ATP-synthase. Variations in the ratio $\mathrm{H}^{+} / \mathrm{ATP}$ are observed and can be explained by the way ATP synthase is operating. The newly synthesized ATP molecules remain bound to the enzyme, and have variable probabilities to be hydrolysed or released from the enzyme, dependent upon the energized state of the membranes. The lowest value found for the ratio, $\mathrm{H}^{+} / \mathrm{ATP}$, is $1.90 \pm 0.55$, which should be very close to the true value.

\section{Introduction}

ATP synthesis on the ATP synthase is reversibly coupled to an $\mathrm{H}^{+}$efflux across the thylakoid membranes, as has been proposed by Mitchell [1]. Thermodynamic considerations have suggested that a minimum of $2.5-3$ protons must be transferred, through the ATP synthase for each ATP molecule synthesized [2,3]. This $\mathrm{H}^{+} / \mathrm{ATP}$ ratio has also been determined experimentally under different conditions: during post-illumination ATP synthesis a ratio of 2.5 was found [4]; in stationary photophosphorylation a ratio of $2-3$ has been reported $[5,6]$; in flash-induced ATP synthesis a mean value of 3.2 was found [7], and external $\mathrm{pH}$ was shown to modulate this value [8]. A ratio of 3 was determined for the reverse reaction, ATP hydrolysis [9]. The largest uncertainty in these measurements of the proton flux across the ATP synthase was the corrections for the proton basic

\footnotetext{
* To whom correspondence should be addressed. Abbreviation: $P_{i}$, inorganic phosphate.
}

conductance of the membrane, not linked to ATP synthesis. Further, actual ATP synthesis must be determined by taking into account the concomitant ATP hydrolysis [9].

Chloroplasts prepared from preilluminated leaves have an active ATP synthase [10,11]. With these chloroplasts we followed, by monitoring the luminescence of the luciferin-luciferase system, the ATP synthesis on separate flashes or groups of flashes [11], given at a frequency of $0.1 \mathrm{~Hz}$. This method offered the convenience of measuring the actual flash-induced ATP synthesis corrected for the dark hydrolysis of ATP. Moreover, the concomitant proton efflux across the membrane could also be determined from the first derivative of the dark decay of the absorbance changes at $515 \mathrm{~nm}$, $\Delta A_{515}$, as a function of time [7]. We already [11] reported variations in the yield of ATP synthesized per flash as a function of the external $\mathrm{pH}$ and of the dark period, $t_{\mathrm{D}}$, between two successive flashes of the flash group. The synthesis of ATP was generally independent on the number of flashes already fired. But with some preparations we observed a lower synthesis of ATP on the first flash 
and a progressive increase on the following flashes, until a limit was reached after the 5 th-10th flashes. In this report we have examined the question whether the ratio $\mathrm{H}^{+}$/ATP varies with the observed yield of ATP synthesized per flash.

We have found that variations of the ratio $\mathrm{H}^{+}$/ ATP do occur following the way flashes are given. These variations are explained by the fate of the ATP molecules bound to the site where they just have been synthesized. These ATP molecules exhibit different probabilities either to be released (and detected by the luciferin-luciferase system in the external medium as ATP) or to be hydrolysed into ADP and inorganic phosphate, $\mathrm{P}_{\mathrm{i}}$. The lowest observed value of $\mathrm{H}^{+} / \mathrm{ATP}$ is 2 and should be very close to the true value.

\section{Materials and Methods}

Procedures were essentially the same as those reported in Ref. 11. Type B chloroplasts [12] with active ATP synthase were prepared from preilluminated leaves of pea seedlings. Experiments were done in hypotonic medium. Absorbance changes at $515 \mathrm{~nm}$, atebrin fluorescence for $\Delta \mathrm{pH}$ determinations and luminescence of the luciferinluciferase system for ATP measurements were followed concomitantly in three different samples of the same chloroplasts suspension. The saturating flashes had a $2 \mu$ s half-time.

Two modifications were introduced. Firstly, concentration of atebrin in all experiments was 0.5 $\mu \mathrm{M}$, and not $2.5 \mu \mathrm{M}$. At this concentration there was no inhibition of the ATP synthesis. Secondly, for all $\Delta A_{515}$ measurements, except for those with groups of two flashes separated by different dark times, $t_{\mathrm{D}}$, the sample was exposed to the measuring beam only during the time of the absorbance measurement at $515 \mathrm{~nm}$, e.g., during $1 \mathrm{~s}$ in every $10 \mathrm{~s}$. When the measuring beam was switched off, the photomultiplier was illuminated by a photodiode to maintain the accuracy of its response.

Calibration of the luciferin-luciferase reaction was done by at least two subsequent additions of 200 picomol ATP from a solution made from a standard kit LKB. Solutions were kept frozen and used only for 1 day experiment after thawing. A calibration by this method allowed us to determine a nucleotide concentration in the ADP solutions used in perfect accordance with the determination made from their absorbance at $260 \mathrm{~nm}$.

With those chloroplasts where ATPase is active addition of ADP in the micromolar range, in the absence of inorganic phosphate, does not decrease the membrane permeability, contrary to what has been observed by $P$. Gräber et al. [13], but increases even slightly the $\Delta A_{515}$ dark decay. So we measured the basic charge flux through the membrane in experiments where ADP and $P_{i}$ were omitted. Calculation of the proton flux across the membrane was done, as in Ref. 7 , from the total charge flux measured in experiments in the presence of ADP and $P_{i}$ by subtracting the basic charge flux measured at the same $\Delta A_{515}$ extent in experiments in the absence of ADP and $\mathrm{P}_{1}$.

From the work of Telfer et al. [14] who used the same material, and by using the absorbance change at $820 \mathrm{~nm}\left(\Delta \varepsilon=6500 \mathrm{M}^{-1} \cdot \mathrm{cm}^{-1}\right)$ measured by Mathis and Setif [15] for P-700 oxidation we find

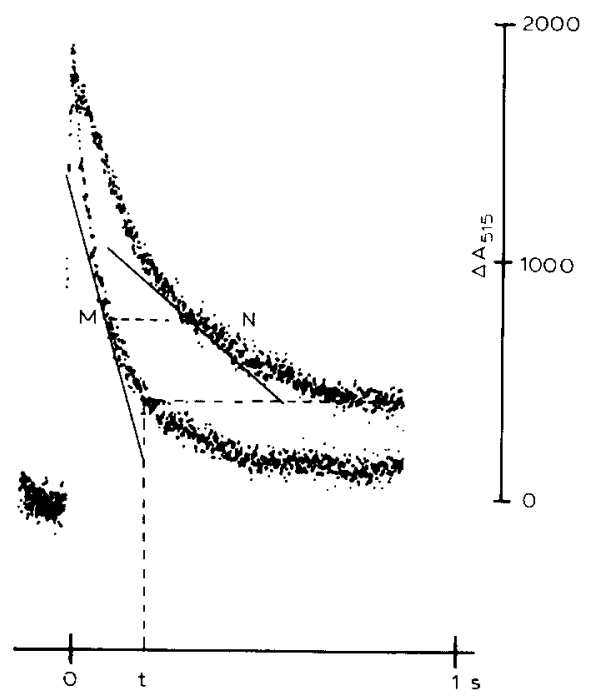

Fig. 1. $\Delta A_{515}$ induced by a group of six flashes, $3 \mathrm{~ms}$ apart. Upper curve corresponds to experiments in the absence of ADP and $P_{i}$, lower curve in the presence of ADP and $P_{i}$. Tangents were drawn at points $M$ and $N$. Their slopes allow to calculate the charge efflux rates. The curves are the mean values of ten signals (signals observed after the 3 rd to the 7 th flash group in two different experiments). Conditions were: 40 $\mathrm{mM}$ Tricine (pH 8), $10 \mathrm{mM} \mathrm{\textrm {MCO } _ { 3 } , 2 0 \mathrm { mM } \mathrm { KHCO }}, 5 \mu \mathrm{M}$ diadenosylpentaphosphate, $0.5 \mu \mathrm{M}$ atebrin and $2 \mathrm{mM} \mathrm{K}_{2} \mathrm{HPO}_{4}$ with $20 \mu \mathrm{M}$ ADP when present. Chloroplasts were equivalent to $40 \mu \mathrm{g}$ of chlorophyll in the $2 \mathrm{ml}$ sample. Temperature was $10^{\circ} \mathrm{C}$. 
one P-700 is oxidized after one single saturating flash per $525 \pm 50$ chlorophylls. In those pea chloroplasts there is always one $\mathrm{P}-700$ per P-680. So we inferred that the $\Delta A_{515}$ induced by a single saturating flash corresponded to one electron or two protons transferred per $525 \pm 50$ chlorophylls more especially as under conditions of our experiments there was no slow rise of the $\Delta A_{515}$.

By using this $\Delta A_{515}$ calibration the charge efflux through the membrane was determined from the first derivatives of the $\Delta A_{515}$ dark decay. The first derivatives were calculated with the multisampler analyser IN 45 (Intertechnique) used to store the signals. In Fig. 1, the proton flux through the ATPase was calculated from the first derivative at point $\mathrm{M}$ minus the one at point $\mathrm{N}$. In experiments where the $\Delta A_{515}$ extent in the presence of ADP and $\mathrm{P}_{\mathrm{i}}$ was lower than the last $\Delta A_{515}$ extent measured in the absence of ADP and $\mathrm{P}_{\mathrm{i}}$ (time above $t_{\mathrm{s}}$ in Fig. 1), a null value was taken for the basic charge flux. The first derivative differences were plotted as a function of time, and integration was done graphically. The area was expressed in number of protons excreted per 1000 chlorophylls.

\section{Results and Discussion}

On ADP addition in the dark we always observed, in the chloroplast suspension, an ATP synthesis which was followed by an ATP hydrolysis. After 5 min equilibration in the dark, the ATP level was approx. $1-2 \%$ of the ADP concentration. On every flash or group of flashes ATP concentration sharply increased, then decreased slowly during the $9 \mathrm{~s}$ dark period between the flashes or flash-groups (Fig 2a). Even at this low frequency $(0.1 \mathrm{~Hz})$ we measured an acidification of the internal compartment of the thylakoids. The proton deposition increased with the number of flashes or flash-groups already fired until a constant level was reached (Fig. 2b). There was no significative difference between the $\Delta \mathrm{pH}$ observed in the presence or in the absence of ADP and inorganic phosphate (Table I).

Onset of photophosphorylation and $\mathrm{H}^{+} /$ATP value

Fig. 3 shows the progressive increase in the yield of ATP synthesis by groups of two flashes, $10 \mathrm{~ms}$ apart, fired at $0.1 \mathrm{~Hz}$ frequency as a func-
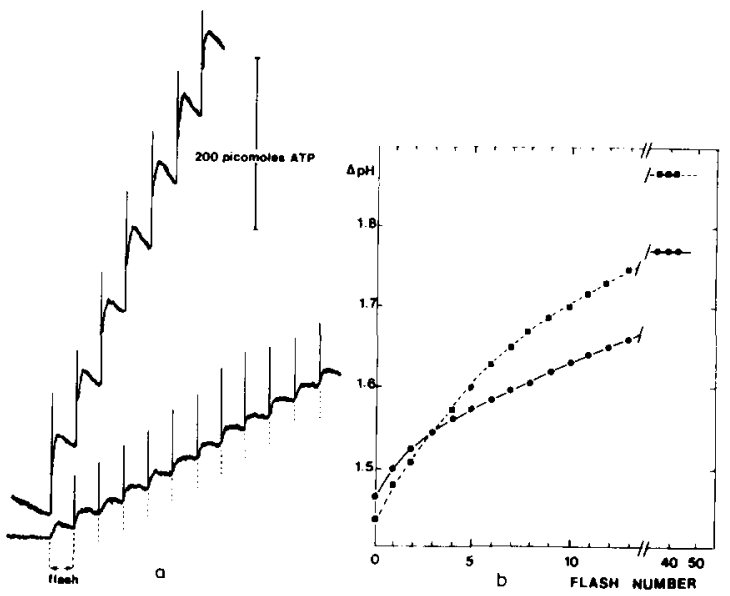

Fig. 2. Flash-induced ATP synthesis and $\Delta \mathrm{pH}$ changes. (a) ATP synthesis induced by single flashes (lower trace) or groups of six flashes, $3 \mathrm{~ms}$ apart (upper trace), given at the frequency of $0.1 \mathrm{~Hz}$. (b) Concomitant $\Delta \mathrm{pH}$ measurements reported by quenching of the atebrin fluorescence. $\square$, groups of six flashes, $3 \mathrm{~ms}$ apart; , single flashes. Conditions were as in Fig. 1. ATP concentrations and $\Delta \mathrm{pH}$ measurements are plotted as a function of the number of single flash or flash-group already fired.

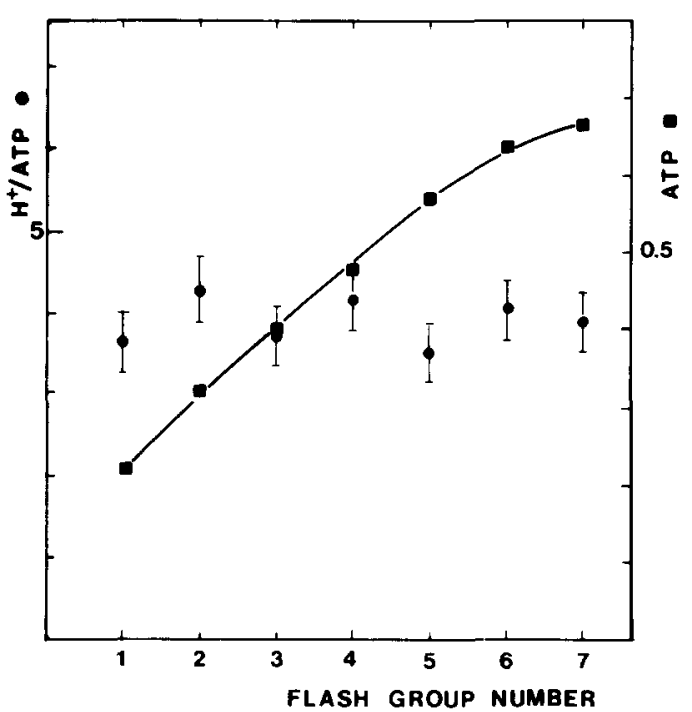

Fig. 3. ATP yield and $\mathrm{H}^{+} / \mathrm{ATP}$ ratio after a group of two flashes, $10 \mathrm{~ms}$ apart, as a function of the number of the flash group. Groups of two flashes, $10 \mathrm{~ms}$ apart were given at the frequency of $0.1 \mathrm{~Hz}$. $\mathrm{E}$, ATP synthesized per 1000 chlorophylls and per flash group; $\bullet$, concomitant $\mathrm{H}^{+}$/ATP ratio. Conditions were as in Fig. 1. Results were the mean value of five different experiments. The bars gave the most probable error. 
TABLE I

\section{$\triangle \mathrm{pH}$ OBSERVED AS A FUNCTION OF THE NUMBER OF FLASHES OR FLASH GROUPS ALREADY FIRED}

Conditions were as in Fig. 2. Measurements were done just before the given flash or flash group was fired. Results were the mean value of respectively $11,4,3$ and 2 determinations (from the left to the right column).

\begin{tabular}{|c|c|c|c|c|}
\hline \multirow{2}{*}{$\begin{array}{l}\text { Flash or flash group } \\
\text { number }\end{array}$} & \multicolumn{2}{|c|}{ Group of six flashes } & \multicolumn{2}{|l|}{ Single flash } \\
\hline & $+\mathrm{ADP},+\mathbf{P}_{\mathrm{i}}$ & No ADP, no $P_{i}$ & $+\mathrm{ADP},+\mathrm{P}_{\mathrm{i}}$ & No $A D P$, no $P_{i}$ \\
\hline $1 \mathrm{st}$ & $1.49 \pm 0.2$ & $1.44 \pm 0.06$ & $1.44 \pm 0.1$ & $1.44 \pm 0.02$ \\
\hline 10 th & $1.69 \pm 0.2$ & $1.65 \pm 0.05$ & $1.58 \pm 0.1$ & $1.54 \pm 0.02$ \\
\hline 20 th & $1.76 \pm 0.2$ & $1.75 \pm 0.04$ & $1.66 \pm 0.07$ & $1.66 \pm 0.03$ \\
\hline 30 th & $1.80 \pm 0.2$ & $1.80 \pm 0.06$ & $1.70 \pm 0.05$ & $1.66 \pm 0.03$ \\
\hline 40th & $1.81 \pm 0.18$ & $1.83 \pm 0.08$ & $1.74 \pm 0.02$ & $1.69 \pm 0.05$ \\
\hline
\end{tabular}

tion of the number of the flash group. The yield of ATP synthesized per 1000 chlorophylls per flashgroup increased from 0.22 for the first group, to a constant yield of 0.65 after the fifth group. There was no concomitant increase of the dark ATPase activity. The ratio of $\mathrm{H}^{+}$/ ATP remained constant between 3.54 and 4.3 .

The increase of the ATP yield cannot be explained by a change in the number of activated ATP synthase molecules, as the dark ATP hydrolysis remained constant. More likely a critical energy threshold for ATP synthesis is overcome by progressive deposition of protons inside the thylakoids, following the number of flash-groups already fired, as we have already shown [16].

$H^{+} / A T P$ value after a group of two flashes as a function of the dark time, $t_{D}$, between the two flashes

We already reported [11] that ATP synthesis after a group of two flashes, $t_{\mathrm{D}}$ ms apart, was more than twice that observed after a single flash when flashes and flash groups were fired at the same frequency, $0.1 \mathrm{~Hz}$. That was particularly obvious at external pH 7. The ATP yield per flash group varied as a function of the dark time $t_{\mathrm{D}}$ between the two flashes of the group, and was maximal for a $t_{\mathrm{D}}$ value of $500 \mathrm{~ms}$ at $\mathrm{pH} 7$ and $1000 \mathrm{~ms}$ at $\mathrm{pH} 8$.

The ratio $\mathrm{H}^{+}$/ATP varied conversely to this ATP yield and was higher after a single flash than after a flash group, especially at external $\mathrm{pH} 7$ (Fig. 4). At first sight the constant stoichiometry between $\mathrm{H}^{+}$and ATP, predicted by the chem- iosmotic theory, is not fulfilled, and the efficiency of the proton transfer through the ATP synthase seems variable. But we must notice that the ATP synthesized per flash corresponds to around 0.5 ATP per 1000 chlorophylls or 0.4 ATP per ATP synthase molecule [17]. Besides the luciferin-luciferase system detects only the ATP free in solution and not the newly synthesized ATP molecules which remain bound to the ATP

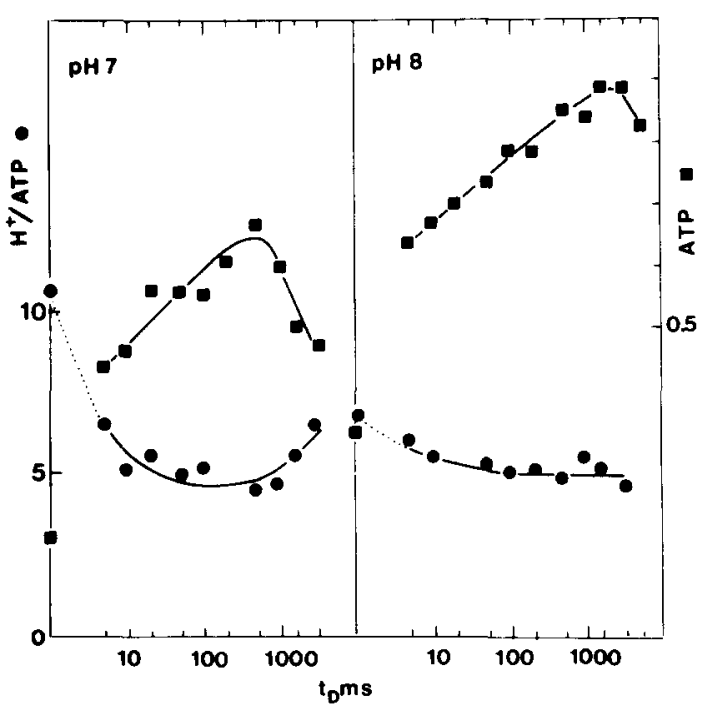

Fig. 4. ATP yield and $\mathrm{H}^{+} /$ATP ratio after groups of two flashes, $t_{\mathrm{D}} \mathrm{ms}$ apart, as a function of $t_{\mathrm{D}}$. Groups of two flashes, $t_{\mathrm{D}} \mathrm{ms}$ apart, were fired at the frequency of $0.1 \mathrm{~Hz}$. ATP synthesized per 10000 chlorophylls per flash group; $\bullet$, Concomitant $\mathrm{H}^{+}$/ATP ratio. Conditions were as in Fig. 1. For $t_{D}=0$ the measurements were done after single flashes fired at the same frequency, $0.1 \mathrm{~Hz}$. 
synthase. The response of the luciferin-luciferase system is so limited by ATP diffusion from the sites where it has been synthesized. Fig. 5 shows that after a flash group the luminescence change, measuring the subsequent ATP concentration increase, takes about $1.6 \mathrm{~s}$ to arrive to completion (response time at half saturation, around $0.8 \mathrm{~s}$ ). This bound ATP can be either released in the medium, or hydrolysed during the dark time between the flashes or the flash groups.

The ATP synthase is a multisite enzyme [18]. We propose that the synthesis of ATP on one site of the ATP synthase facilitates the release of the previously synthesized ATP bound to another site of the same enzyme molecule. We have some hints to predict such a flip-flop mechanism for ATP hydrolysis on the soluble part, $\mathrm{CF}_{1}$, of the ATP synthase [19]. Thus the ATP synthesized after the first flash of the group is released when a new ATP is synthesized after the second flash and does not experience hydrolysis to ADP and $P_{i}$. In this way we can explain the lower ratio $\mathrm{H}^{+}$/ ATP after

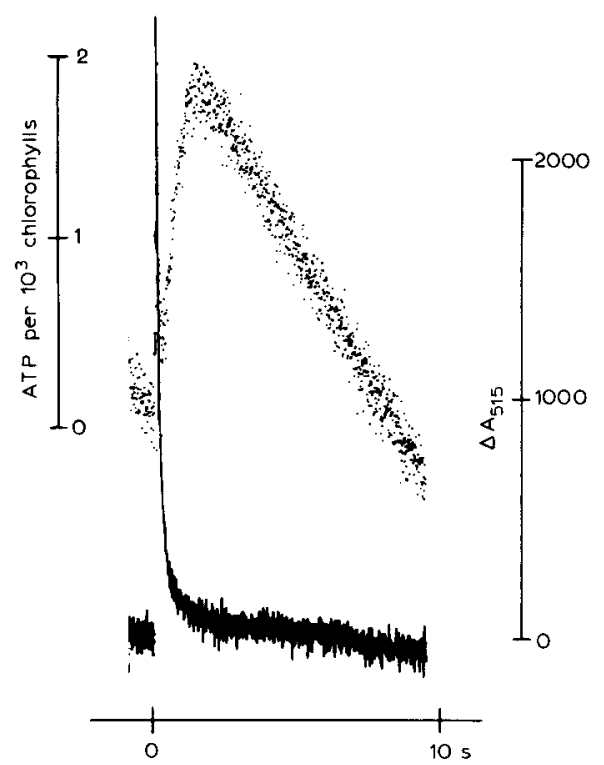

Fig. 5. Absorbance changes at $515 \mathrm{~nm}$ and luminescence of the luciferin-luciferase system as a function of the time after a flash group. Groups of six flashes, $3 \mathrm{~ms}$ apart, were fired at frequency of $0.1 \mathrm{~Hz}$. Conditions were as in Fig. 2, but chloroplast concentration was equivalent to $40 \mu \mathrm{g}$ of chlorophyll per ml. $\Delta A_{515}$, continuous line, was the mean value of ten consecutive determinations and luminescence, dotted line, the mean value of $\mathbf{4 0}$ determinations. a flash group rather than a single flash.

When the dark time $t_{\mathrm{D}}$ between the two flashes of the group increases beyond a certain value, the bound ATP has a high probability of being hydrolyzed during this time, and the ATP released from the site after the second flash decreases. This explains the increase of the $\mathrm{H}^{+} / \mathrm{ATP}$ for $t_{\mathrm{D}}$ values higher than $500 \mathrm{~ms}$ at $\mathrm{pH} 7$ or 1-2 s at $\mathrm{pH} 8$.

For the shortest times, the efficiency of the second flash of the group is maximum only when it is fired after a certain delay, $500 \mathrm{~ms}$ at external pH 7 or $1000 \mathrm{~ms}$ at $\mathrm{pH} \mathrm{8,} \mathrm{after} \mathrm{the} \mathrm{first} \mathrm{flash.} \mathrm{That}$ means that after the first flash either the ATPase takes a certain time to recover a conformation sensitive to the effect of the second flash, or the energy stored after the first flash needs a certain time to be available on the second flash. We favour the first explanation, as there is no changes in the redox state of components of the electrontransfer chain in the same time range.

\section{Variability of the $H^{+} / A T P$ ratio}

This ratio was measured after groups of six flashes, $3 \mathrm{~ms}$ apart, given at a frequency of $0.1 \mathrm{~Hz}$. In these conditions we observed the maximum extent of the absorbance changes at $515 \mathrm{~nm}, \Delta A_{515}$. The measurements were done for the 3 rd to the 7th flash group and for the 21st to the 40th flash group. In this way we did not take into account the variations in ATP synthesis sometimes observed after the 1st and 2nd flash group. For each experiment the two determinations were identical and their values are given in Table II.

Within the precision of the measurements, the ratio of $\mathrm{H}^{+} /$ATP was constant for the same chloroplast preparation, whatever was the number of flash group already fired. Table II shows that even under conditions where the yield of ATP synthesized is decreased by 'aging' of the chloroplasts or by the addition of nanomolar concentrations of nigericin, the ratio of $\mathrm{H}^{+} /$ATP remained constant.

In the presence of nigericin and potassium ions we found an increase of the membrane proton permeability, and so a general decrease of the transmembrane proton electrochemical potential difference, $\Delta \tilde{\mu} H$. In those conditions we expected a progressive increase of the ATP synthesized with the number of flash group already fired as in 
TABLE II

ATP YIELD AND $H^{+}$/ATP RATIO AFTER GROUPS OF SIX FLASHES, 3 ms APART, AS A FUNCTION OF THE CHLOROPLAST PREPARATION AND OF THE TIME OF THEIR CONSERVATION

Conditions were as in Fig. 2. In experiment 2 we gave the mean value of two consecutive determinations. The experimental results, giving the ratio $\mathrm{H}^{+} / \mathrm{ATP}$, correspond to: the first value (left) observed for the 3 rd to the 7 th flash group, the second value (right) observed for the 21 st to the 40th flash group. Taking into account the dispersion of the mean values and the probable error on the number of charges transferred per single saturating flash, the ratio $\mathrm{H}^{+} / \mathrm{ATP}$ is: $3.40 \pm 0.8,2.25 \pm 0.7,3.90 \pm 0.8,1.90 \pm 0.55$ in experiments 1, 2, 3 and 4, respectively. The concomitant measurements made with single flashes, fired at the same frequency, gave: experiment $1: \mathrm{H}^{+} / \mathrm{ATP}=3.23$ for $0.47 \mathrm{ATP}$ synthesized per flash and 1000 chlorophylls, experiment $2: \mathrm{H}^{+} / \mathrm{ATP}=4.96$ for 0.34 ATP per flash and 1000 chlorophylls.

\begin{tabular}{|c|c|c|c|c|c|}
\hline \multirow{2}{*}{$\begin{array}{l}\text { Experiment } \\
\text { number }\end{array}$} & \multirow{2}{*}{$\begin{array}{l}\text { Time that chloro- } \\
\text { plasts were kept } \\
(\mathrm{min})\end{array}$} & \multirow{2}{*}{$\begin{array}{l}\text { Nigericin } \\
(\mathrm{nM})\end{array}$} & \multicolumn{2}{|l|}{$\mathrm{H}^{+} / \mathrm{ATP}$} & \multirow{2}{*}{$\begin{array}{l}\text { ATP / flash group } \\
1000 \text { chlorophylls }\end{array}$} \\
\hline & & & $\begin{array}{l}\text { Experimental } \\
\text { results }\end{array}$ & $\begin{array}{l}\text { Mean } \\
\text { values }\end{array}$ & \\
\hline \multirow[t]{4}{*}{1} & 20 & 0 & $2.74-3.49$ & 3.11 & 1.36 \\
\hline & 120 & 0 & $3.19-3.33$ & 3.26 & 1.02 \\
\hline & 140 & 0 & $3.75-3.45$ & 3.60 & 0.7 \\
\hline & 160 & 0 & $3.27-3.73$ & 3.50 & 0.84 \\
\hline 2 & $20-40$ & 0 & $2.03-2.47$ & 2.26 & 1.72 \\
\hline \multirow[t]{5}{*}{3} & 0 & 0 & $3.22-4.38$ & 3.80 & 1.51 \\
\hline & 100 & 2.5 & $2.78-4.99$ & 3.89 & 0.41 \\
\hline & 140 & 0.5 & 3.60 & 3.60 & 0.84 \\
\hline & 200 & 0.1 & $3.78-4.02$ & 3.90 & 0.85 \\
\hline & 240 & 0 & $4.47-3.93$ & 4.20 & 1.01 \\
\hline \multirow[t]{5}{*}{4} & 0 & 0 & $1.57-1.74$ & 1.65 & 2.75 \\
\hline & 40 & 0 & $1.59-2.11$ & 1.85 & 1.98 \\
\hline & 60 & 1 & $2.26-1.87$ & 2.07 & 1.67 \\
\hline & 100 & 5 & $1.69-2.10$ & 1.90 & 1.61 \\
\hline & 160 & 0 & $2.47-1.67$ & 2.07 & 2.26 \\
\hline
\end{tabular}

experiments reported in Fig. 3. But, in the range of the nigericin concentration used, ATP synthesis was already maximum after the first flash group and remained constant on the following flash groups.

For the different chloroplast preparations the mean value of $\mathrm{H}^{+}$/ATP ranged from approx. 4 to 2. Until now we have not been able to correlate these different values with changes in the $\Delta \mathrm{pH}$ measured or in the concentration of the free ATP. We propose that this variability is directly linked to the variable probability of hydrolysis of the new synthesized ATP bound to the ATP synthase in the different chloroplast preparations. This proposal is supported by the observed acceleration of the dark decay of the flash-induced absorbance changes at $515 \mathrm{~nm}$ in the presence of ATP, especially when inorganic phosphate is present [10]. In this latter case, the acceleration of $\Delta A_{515}$ dark decay is caused by the supplementary proton efflux through the ATP synthase linked to a flashinduced ATP synthesis from the ADP formed by hydrolysis of the bound ATP and remaining bound to the enzyme. Thus this additional proton efflux is not related to a true ATP synthesis, but to an equilibrium between bound ATP and bound ADP plus inorganic phosphate, that is to say to an exchange between the $\gamma$-phosphoryl group of ATP with inorganic phosphate $[9,20]$.

\section{Conclusion}

Our results emphasize the necessity of taking into account hydrolysis of the newly synthesized ATP molecules to get correct values of the ratio $\mathrm{H}^{+} / \mathrm{ATP}$. From the $\Delta A_{515}$ and ATP concentration changes measured as a function of the time we could expect to measure the true value of this 
ratio. But technical difficulties are encountered. First the response of the luciferin-luciferase assay system is limited by the diffusion of ATP from the ATP synthase and the luminescence changes observed after a flash or a flash-group is slow, $t_{1 / 2}=$ $0.8 \mathrm{~s}$ (Fig. 5). A direct comparison, at each time, between the ATP concentration and $\Delta A_{515}$ changes is not possible. Proton efflux across the ATPase is too fast, and is completed within $0.5 \mathrm{~s}$ after the flash group. ATP hydrolysis in the dark time between the flash groups should change the kinetics of the $\Delta A_{515}$ dark decay, and could be so related with a proton influx. But observation of the $\Delta A_{515}$ in between two flash groups is of no meaning as the reliability of the measurements is low because of the lack of stability of the base line in longrange-time spectroscopic measurements. On the other hand we measure only the ATP free in the suspension. So for these reasons we compare free ATP synthesized after a flash group by taking into account the concomitant-free ATP hydrolyzed (inferred from the rate of ATP hydrolysis in the dark time between the flash groups) with the calculated proton efflux through the ATPase (within around $0.5 \mathrm{~s}$ after the flash group). So we measure only an apparent $\mathrm{H}^{+}$/ ATP ratio which should be higher than the true one as we underestimate the amount of ATP synthesized, bound and free.

The last point to take into account is the reliability of the measurement of the proton flux through the ATP synthase. We have made the assumption that at the same value of the $\Delta A_{515}$ observed, in the presence and in the absence of ADP and $\mathrm{P}_{\mathrm{i}}$, corresponds a same value of the $\Delta \tilde{\mu} \mathbf{H}$ and consequently of the basal flux of charges across the membrane. We suppose that just before the flash is fired the two components of this $\Delta \tilde{\mu} \mathrm{H}$, $\Delta \mathrm{pH}$ and preflash membrane potential difference are identical in the two experimental conditions. In fact, even if the $\Delta \mathrm{pH}$ increases, as a function of the number of flash groups already fired, we have shown (Table I) that it remains the same in the absence and in the presence of ADP and $P_{i}$. Slow membrane-potential changes can be recorded by absorbance changes of oxonol VI [21]. We have never seen, before or after ADP and $P_{i}$ addition, any absorbance change of this dye, reversed by $\mathrm{KSCN}$ or valinomycin and potassium ions, in complete darkness or within the $50 \mathrm{~s}$ time period following series of flashes. The best justification of the method used is the constancy of the ratio $\mathrm{H}^{+}$/ ATP observed at the different periods of the series of flash groups or after nigericin addition. In the last case the basic proton flux is considerably enhanced.

The apparent values of the ratio $\mathrm{H}^{+}$/ATP reported in Table II vary from approx. 2 to 4 . We think those differences are not the result of indeterminate errors and we are not allowed to calculate an average value. We remark that the higher the ratio of ATP synthesized after a flash group to this synthesized after a single flash, the lower the apparent $\mathrm{H}^{+} / \mathrm{ATP}$ ratio that was found. The faster the turnover of the flash-induced ATP synthesis, the lower the stay of ATP on the enzyme and the lower the ratio $\mathrm{H}^{+} / \mathrm{ATP}$. That means we found the lower the $\mathrm{H}^{+}$/ ATP ratio in conditions where newly synthesized ATP, bound to the enzyme, has the lower the probability to be hydrolyzed before its release in the medium. Such variations of this ratio $\mathrm{H}^{+}$/ ATP have been reported for ATP synthesis on Escherichia coli membranes, photosynthetic bacteria chromatophores and mitochondria $[22,23]$. The lower apparent value we found, $2 \mathrm{H}^{+}$per ATP, must be taken into account and should be very close to the true value.

\section{References}

1 Mitchell, P. (1966) Biol. Rev. Cambridge Phil. Soc. 41, 445-502

2 Gräber, P. and Witt, H.T. (1976) Biochim. Biophys. Acta 423, 141-161

3 Avron, M. (1978) FEBS Lett. 96, 225-232

4 Izawa, K. (1970) Biochim. Biophys. Acta 223, 165-173

5 Schröder, H., Muhle, H. and Rumberg, B. (1972) in Proceedings of the 2nd International Congress on Photosynthesis (Forti, G., Avron, M. and Melandri, A., eds.), Vol. II, pp. 919-930, Dr. W. Jung Publishers, Dordrecht, The Netherlands

6 Schwartz, M. (1968) Nature (Lond.) 219, 915-919

7 Junge, W., Rumberg, B. and Schröder, H. (1970) Eur. J. Biochem. 14, 575-581

8 Schloder, E., Rögner, M. and Witt, H.T. (1982) FEBS Lett. $138,13-18$

9 Davenport, J.W. and McCarty, R.E. (1981) J. Biol. Chem. 256, 8947-8954

10 Girault, G. and Galmiche, J.M. (1978) Biochim. Biophys. Acta $502,430-444$

11 Galmiche, J.M. and Girault, G. (1982) FEBS Lett. 146, 123-128

12 Hall, D. (1972) Nature New Biol. 235, 125-126 
13 Gräber, P., Burmeister, M. and Hortsch, M. (1981) FEBS Lett. 136, 25-31

14 Telfer, A., Bottin. H., Barber, J. and Mathis, P. (1984) Biochim. Biophys. Acta 764, 324-330

15 Mathis, P. and Setif, P. (1981) Isr. J. Chem. 21, 316-320

16 Galmiche, J.M. and Girault, G. (1984) in Advances in Photosynthesis Research (Sybesma, C., ed.), Vol. II, pp. 379-382, Martinus Nijhoff/Dr. W. Junk Publishers, Dordrecht, The Netherlands

17 Strotmann, H., Hess, H. and Edelman, K. (1974) Biochim. Biophys. Acta 314, 202-210

18 Strotmann, H, and Schumann, J. (1983) Physiol. Plant. 57, 375-382
19 Girault, G., Galmiche, J.M., Lemaire, C. and Stulzaft, O. (1982) Eur. J. Biochem. 128, 405-411

20 Wimmer, M.J. and Rose, I.A. (1977) J. Biol. Chem. 252, 6769-6775

21 Galmiche, J.M. and Girault, G. (1980) FEBS Lett. 118, $72-76$

22 Vink, R., Robin Bendall, M., Simpson, S.J. and Rogers, P.J. (1984) Biochemistry 23, 3667-3675

23 Baccarini-Melandri, A., Casadio, R. and Melandri, B. (1981) Curr. Top. Bioenerg. 12, 197 258 